\title{
Work Posture Assessment with Application (Quick Exposure Check) at Boiler Stations
}

\author{
Ikhsan Siregar ${ }^{1}$, Ridhaul Fuad ${ }^{2}$, Yusuf Hanifiah ${ }^{3}$ \\ 1, 2,3 Department of Industrial Engineering, University of Sumatera Utara, Indonesia \\ ikhsan.siregardusu.ac.id \\ Siregar ix@yahoo.com \\ The.snake.diveregmail.com
}

\begin{abstract}
This research is in farm manufacturing. The manufacturing is less aspect health and occupational safety (K3) for each worker, especially in the boiler workers. Element works at the boiler station the disposal of burning done manually and repeatedly. Activity manual work done this repeating if done in long period of time, will cause injured 'musculoskeletal' which led to declines in productivity company. It needs to be an assessment of posture work at the station boiler so as not to cause risk injured. The method used to assess the relative posture work is the method quick exposure check (QEC). QEC is a method of assessment using a questionnaire as an instrument to analyze posture work perceived workers for does its work. The research results show that the score exposure from workers at the station boiler high, so that need to be taken of action investigation and improved soon as soon as possible. The score exposure workers Operator 1 is 67,04\%, workers Operator 2 is $69,31 \%$ and Operator 3 is $64,77 \%$
\end{abstract}

Keywords - Musculoskeletal, Work Posture, Quick Exposure Check (QEC), Operator, occupational safety.

\section{INTRODUCTION}

Increase the productivity is an important effort that a company should do in order to survive and to develop the business. One of the things that support employee productivity is the ergonomic aspects. The main factors in the work system based on ergonomic aspects are human. This principle is called human centered design, human as a planner, planning, executing, controlling, and evaluators the whole working system in order to obtain a good work.

There are many research on working postures had been done in many places of the world. This research is endless; this is because the amount of equipment and working methods are wrong in doing his job. This is very harmful to the operator while working. In a previous study, in the Malaysian state electronics company in researching about the pain behind the workers, the conclusion obtained that companies should review and provide a schedule extra rest for workers [1]. Other studies on worker posture while standing, standing where necessary tools to prevent injury [2]. The case study on nurses in hospitals in the United States that are common injuries in nurses when carrying out the work, it is clearly stated that all the work had nearly the same risk [3]. Human posture who suffered injury not only in adults, but can also afflicts children [4]. There is even a study that examines the tattoo artist to work posture when carrying out work [5]. Several studies before were conducted outside Indonesia, while research in Indonesia is researching on muscle injury when carrying out the work of Stamping Batik (Batik Cap) [6]. Another study conducted in Indonesia is like the research about operators using manual material handling, which found many workers who feel sick at the time after doing the work [7].

To use methods Quick Exposure Check (QEC), previous research studies conducted about the taxi drivers in Turkey, through the study found that the taxi drivers prone to injury when doing work [8].

The research looked at posture assessment workers in the boiler workstation; it is because of the many complaints from workers at that workstation. Assessment of the risk of musculoskeletal workers at Sei Semayang Sugar Factory boiler station is based on work that performed by circumstances that can cause injury. Non-ergonomic working postures in the boiler station for long periods of time have a higher risk of musculoskeletal. Through this research is expected a solution for Operator to feel comfort working at his job.

\section{METHOD}

The object of this research is the workers who perform work in the boiler stations with poor 
environmental conditions. Workers who observed in this study is as many as three people. Schematically, the steps of the study can be seen in Fig. 1.

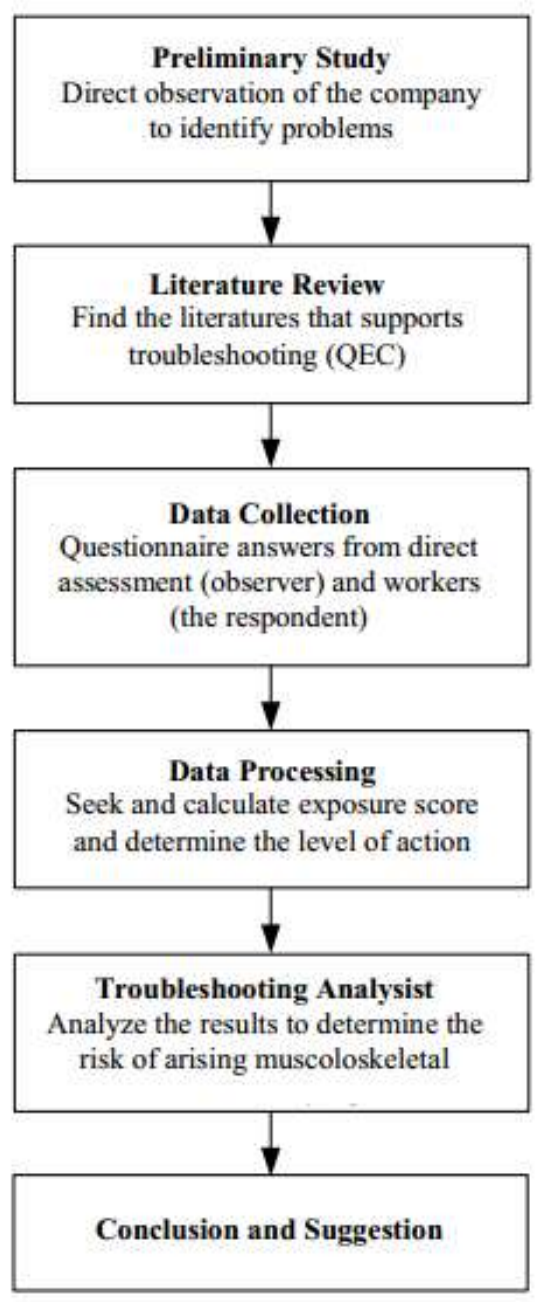

Fig. 1. Research Method Block Diagram

Steps being taken in the study

\section{Preliminary Study}

Preliminary study was conducted to determine the working conditions of the company to be used as the basic framework of thinking for analyzing the problems to be studied.

\section{Literature Review}

The study of literature are theories that are used in problem solving. Study of literature as the basis for logical thinking in solving the problem scientifically.

\section{Data Collection}

The data taken is the primary data, is the data obtained from direct observations and research in the field. Data taken form the QEC questionnaire answers from direct assessment (observer) and workers (respondent).

\section{Data Processing}

Data already collected and processed by the method of QEC (Quick Exposure Check). In this case, assessed and calculated exposure scores of each working element then will be presented to get the level of action to be taken in the risk of musculoskeletal experienced workers.

\section{Troubleshooting Analysist}

Based on the results obtained from the data processing, do the troubleshooting analysist. The analysis was performed in order to see whether the method used has been able to identify musculoskeletal risk so do the proposed improvement.

\section{Conclusion and Recommendations}

Based on data processing and discussion it can be concluded about the studied problems and provide suggestions for improvement in the future related research.

\section{RESUlTS AND DisCUSSIONS}

QEC questionnaire given to all workers at the boiler work station and observers also assess how the worker's body posture when working. QEC questionnaire for observers and workers are different, but both are used to analyze the condition of a work station. Questionnaires of observers pay more attention to the body posture during activity. While the workers questionnaire lead to the perceived felt by workers while doing his job. 


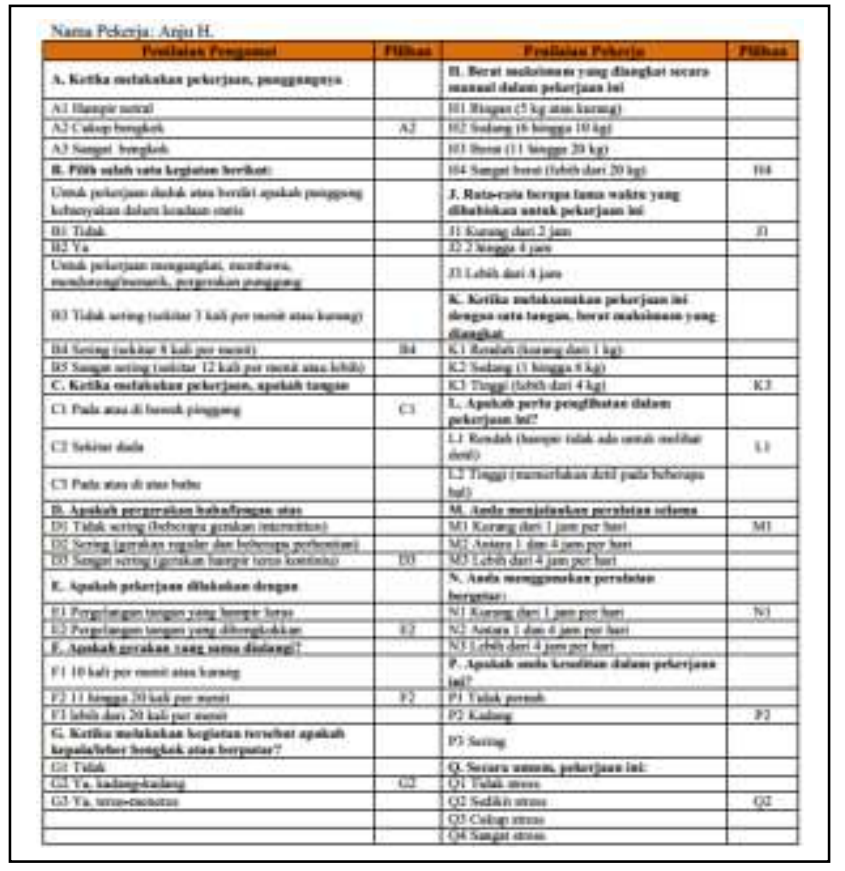

Fig. 2. QEC (Quick Exposure Check) Questionnaire Data

TABLE I

OBSERVER QUESTIONNAIRE ANSWER RECAPITULATION

\begin{tabular}{|l|c|c|c|c|c|c|c|}
\hline \multirow{2}{*}{$\begin{array}{c}\text { Name } \\
\text { Worker }\end{array}$} & \multicolumn{2}{|c|}{ Back } & \multicolumn{2}{c|}{ Shoulder } & \multicolumn{2}{c|}{ Neck } & \multirow{2}{*}{ Wrist } \\
\cline { 2 - 7 } & $\mathbf{1}$ & $\mathbf{2}$ & $\mathbf{1}$ & $\mathbf{2}$ & $\mathbf{1}$ & $\mathbf{2}$ & \\
\hline Anju H. & A2 & B4 & C1 & D3 & E2 & F2 & G2 \\
\hline Tandra & A2 & B4 & C2 & D3 & E2 & F2 & G2 \\
\hline Jogi T. & A2 & B4 & C1 & D2 & E2 & F2 & G2 \\
\hline
\end{tabular}

TABLE II

WORKER ANSWER QUESTIONNAIRE RECAPITULATION

\begin{tabular}{|l|c|c|c|c|c|c|c|c|}
\hline $\begin{array}{c}\text { Workers } \\
\text { Name }\end{array}$ & \multicolumn{7}{|c|}{ Question } \\
\cline { 2 - 9 } & H & J & K & L & M & N & P & Q \\
\hline Anju H. & H4 & J1 & K3 & L1 & M1 & N1 & P2 & Q2 \\
\hline Tandra p. & H4 & J1 & K3 & L1 & M1 & N1 & P2 & Q2 \\
\hline Jogi T. & H4 & J1 & K3 & L1 & M1 & N1 & P2 & Q2 \\
\hline
\end{tabular}

The answers obtained from the questionnaires will then be used to calculate the exposure value score. Example of the calculation are carried out on the QEC score sheet like shown at Figure 3.

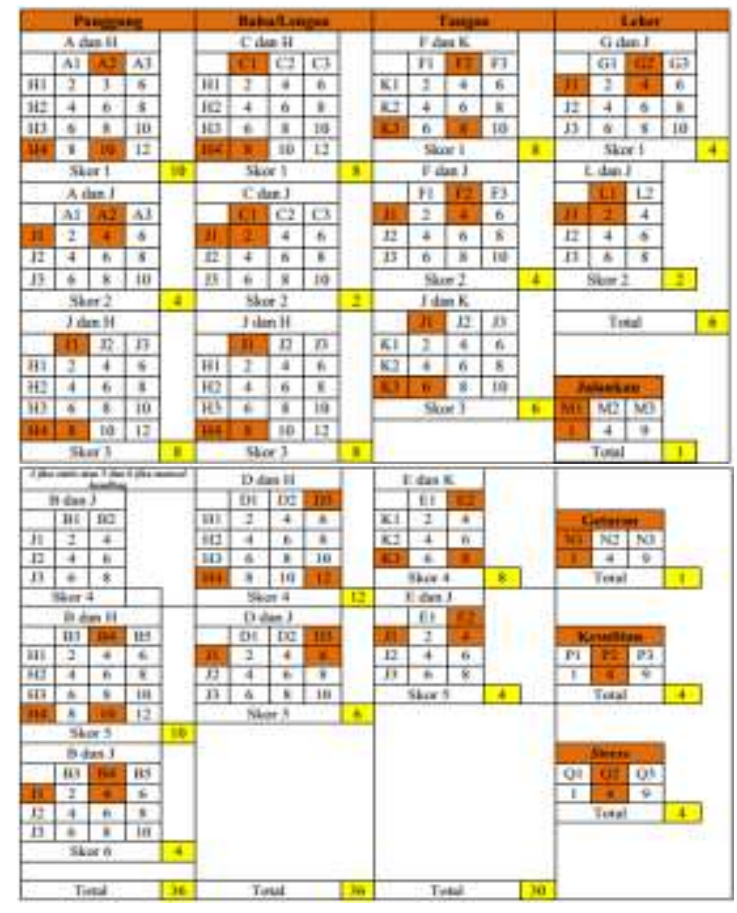

Fig. 3. QEC Score Sheet

The results of expsosure calculation will then be calculated by using the formula:

$$
\mathrm{E}(\%)=\mathrm{X} \times \frac{100 \%}{\mathrm{X}_{\max }}
$$

$\mathrm{X}=$ The total scores obtained for the exposure to the risk of injury to the back, shoulders/arms, wrists and neck that obtained from questionnaires calculation

$\mathrm{Xmax}=$ The total maximum score for exposure that may occur injury to back, shoulder/arm, wrist and neck.

$\mathrm{Xmax}$ for static work is 162

Xmax for manual handling work 176

The following calculations of QEC assessment for worker Anju $\mathrm{H}$.

$$
\begin{array}{ll}
\mathrm{X} & =36+36+30+6+1+1+4+4=118 \\
\mathrm{Xmax} & =176
\end{array}
$$

The exposure score $(\mathrm{E})$ is:

$\mathrm{E}=\frac{118}{176} \times 100 \%=67,04 \%$

Based on the assessment of the elements of the work of the combustion disposal in the boiler station, indicating that elements of the work at the station boilers require investigation and repair immediately. This is proved by the existence of 
errors work posture (working posture is not good), causing back and shoulder/arm scores high. Thus, the risk of musculoskeletal for the worker is quite dangerous if it is continued without repairs.

Based on the results of the assessment by the QEC method showed that elements of the work at the station boilers require urgent repairs so that the risk of musculoskeletal experienced enough workers at risk. Improvements that can be proposed as a solution to the problem is to reduce the maximum weight lifted manually in this work.

TABLE III

EXPOSURE SCORE RECAPITULATION AND ACTIONS LEVEL

\begin{tabular}{|c|c|c|}
\hline Name & Score (\%) & Actions \\
\hline Anju H. & 67,04 & $\begin{array}{c}\text { Immidiate investigation and } \\
\text { refurbishment }\end{array}$ \\
\hline Tandra P. & 69,31 & $\begin{array}{c}\text { Immidiate investigation and } \\
\text { refurbishment }\end{array}$ \\
\hline Jogi T. & 64,77 & $\begin{array}{c}\text { Immidiate investigation and } \\
\text { refurbishment }\end{array}$ \\
\hline
\end{tabular}

\section{CONCLUSIONS}

Based on the results of conducted research can be concluded:

1. Exposure Score causing musculoskeletal risk of workers at the station boiler for workers Anju $\mathrm{H}$ is $67.04 \%$, workers Tandra $\mathrm{P}$ is $69.31 \%$ and workers Jogi $\mathrm{T}$ is $64.77 \%$.

2. Level of action that should be taken to improve musculoskeletal risk is the immediate investigation and prompt repair.

3. The risk of musculoskeletal experienced by workers in the boiler station is high and quite dangerous. This musculoskeletal high risk assessment located at the back, shoulders/arms and hands. This is due to unfavorable working facilities.

\section{ACKNOWLEDGMENTS}

The authors gratefully acknowledge that the present research is supported by University of Sumatera Utara. Last, but not least thank to my wife, my son and my daughter, without whom I was nothing; they not only assisted me morally but also extended their support emotionally.

\section{REFERENCES}

[1] Aziz, Roseni Abdul, Effect of Working Posture on Back Pain Occurrence among Electronic Workers in Malaysia,Procedia Manufacturing 2 ( 2015 ) $296-300$

[2] Fewster, Kayla M., The effect of standing interventions on acute lowback postures and muscle activation patterns, Applied Ergonomics 58 (2017) 281-286

[3] Schall Jr., Mark C. , Working postures and physical activity among registered nurses, Applied Ergonomics 54 (2016) 243-250

[4] Schwanke, Natalí Lippert . Differences in body posture, strength and flexibility in schoolchildren with overweight and obesity: A quasiexperimental study, Manual Therapy 22 (2016) 138-144

[5] Keester, Dana L., Investigation of musculoskeletal discomfort, work postures, and muscle activation among practicing tattoo artists, Applied Ergonomics 58 (2017) 137-143

[6] Sutaria, Wiyono, Analysis of working posture on muscular skeleton disorders of operator in stamp scraping in 'batik cap' industry, Procedia Manufacturing 4 ( 2015 ) 133 - 138.

[7] Wahyudi, M. Arip, Work Posture Analysis of Manual Material Handling Using OWAS Method, Agriculture and Agricultural Science Procedia 3 ( 2015 ) 195 - 199

[8] Bulduk, Emre €Ozgür, Assessing exposure to risk factors for work-related musculoskeletal disorders using Quick Exposure Check (QEC) in taxi drivers, International Journal of Industrial Ergonomics 44 (2014) 817 820 